\title{
Cardiological instrument for assistance in the elderly's terminal life: parameters of medicine and nursing
}

\section{Abstract}

Goal: Describe the use of a cardiological instrument developed by medicine and nursing with the use of information technology to assist terminally ill elderly patients.

Introduction: The use of interventional medical technology in cardiac and terminally ill elderly patients needs to be associated with palliative care as clinical support measures in intensive care. This resource assists in decisions at the end of the patient's life and directs the attention of the health team to ensure patient comfort and family satisfaction. In this regard, information and communication technology assist the entire care process.

Method: It is a descriptive and exploratory study of quantitative and statistical character. Based on the innovative methodology of the current times, using uniform and ethical parameters for the elaboration of assistance based on auxiliary technology and the knowledge of medical and nursing professionals.

Results and Discussion: 99 articles were analyzed, discussed and quantified, showing experiences of palliative care in intensive care units using the variables of technology and cardiologic instruments and the participation of medicine and nursing.

Conclusion: The theme "palliative care" should be further investigated in order to improve the relationship between patients, their families and the health team. Considering the increase in the number of elderly people in intensive care, it is essential to improve the training of health professionals to face the challenges that involve the end of life and cardiology.

Keywords: elderly, medicine, nursing, technology, palliative care, cardiology
Volume 5 Issue 2 - 2020

Souza MC, Luiz Amaro do Nascimento Neto, Lucas Afonso Barbosa Saraiva, Caio Vinicius Afonso Barbosa Saraiva, Ariosto Afonso de Morais, Thais MonaraBezerra Ramos, JúliaRafaelly de Matos Barbosa Jordão

Nurses and Doctors (Independent Intellectual Researchers), Individual Academic League, Medicine Clinic, Federal University of Pernambuco (UFPE), Brazil

Correspondence: Souza MC, Medicine Clinic, Federal University of Pernambuco (UFPE), Brazil, Tel 8|98|255845, Email Article_ufpe@hotmail.com

Received: March 22, 2020 | Published: April 09, 2020

\section{Introduction}

It is understood that the global need for palliative care in intensive cardiological therapy is increasing due to the increase in chronic non-communicable diseases and the aging of the population. In this scenario, cardiovascular diseases, which account for 39\% of the 40 million people who need palliative care each year. However, due to the increasing prevalence of Heart Failure (HF) and the high burden of symptoms that the disease causes, when compared with patients with malignant diseases, the literature points out that patients with heart failure hardly receive palliative care and, when they receive it, care differs qualitatively and quantitatively. ${ }^{1}$

The development of a cardiological instrument with the help of information technology and medical and nursing communication, helps a lot in this sense of assistance, as it is explained that this is because HF presents a set of challenges to the effective implementation of palliative care. Throughout the course of HF, patients face periods of acute exacerbation producing a non-linear and unclear trajectory. Thus, despite the various guidance tools, the unpredictability of this condition leads to prognostic uncertainty about progression, exacerbation or death. Patients' lack of knowledge about their condition and insufficient communication between professionals are also barriers. ${ }^{1,2}$

According to international data $(89 \%)$, that patients with $\mathrm{HF}$ generate a high health cost due to the amount of resources used in the last five months of life. A survey conducted at five hospitals in New York (NY) showed that patients who received palliative care reduced the hospital cost by about eight thousand dollars when compared to those who received usual care. Therefore, the effectiveness of palliative care is revealed not only in preserving the patient's dignity and quality of life, but also in the economic sphere. ${ }^{3}$

It is known that working with palliative care requires dealing not only with physical needs, but with the spiritual, psychological and social domains. Skills are needed to understand death as a natural life process, support the patient and family in the constant redefinition of realistic hopes, communicate effectively and constantly with the patient, health team and family, including bad news, and understand, in fact, the concept of palliative care and that there is no conflict between the administration of therapies aimed at prolonging survival and palliative care. ${ }^{3.4}$ 
Therefore, the objective of this study is Describe the use of a cardiological instrument developed by medicine and nursing with the use of information technology to assist terminally ill elderly patients. With the justification that the information and communication technology for the elaboration of the cardiologic instrument was sufficient to assist medicine and nursing, so that new studies can be elaborated and the scientific academy has more access to quality content in accordance with statistic data. ${ }^{5}$

The guiding question arises: Will medicine and nursing be able to offer differentiated and quality assistance in the cardiac ICU, palliative care to elderly people in terminal life with the innovative use of information and communication technology?

\section{Method}

It is a descriptive and exploratory study of quantitative and statistical character. Based on the innovative methodology of the current times, using uniform and ethical parameters for the elaboration of assistance based on auxiliary technology and the knowledge of medical and nursing professionals. The present study was also an integrative survey of the literature with regard to the cardiological instrument in palliative care and the terminality of life of the geriatric population. This method aims to group and synthesize research results on a given topic, in an organized way so that it contributes to a deepening of knowledge on the issue addressed. ${ }^{5}$

This method has been used in the production of articles, dissertations and theses in the health area in recent decades. A statistical survey of the literature was also carried out on scientific productions based on the cardiological instrument in intensive care, terminal life and palliative care of the elderly population, in the national and international context, in the area of health. This method allows " $[. .$. the search, critical evaluation and synthesis of the available evidence on the investigated topic". ${ }^{6}$

The use of this method allows, as a result, the current situation of knowledge on the topic addressed, the implementation of interventions in health care and the identification of gaps that need further study on the subject. To elaborate this study, the six steps of the scientific methodology mentioned by Mendes, Silveira and Galvão were used in order to organize the information collected. ${ }^{7}$

1st stage: elaboration of the guiding question. Its definition is the most important phase, as it determines the identification of what must be addressed to contemplate the proposed theme. ${ }^{8}$

2nd stage: search or sample in the literature. The search was carried out in a wide and diversified way in the reliable databases, taking into account that the determination of the inclusion and exclusion criteria for selection of the material should be carried out in accordance with the guiding question. ${ }^{9}$

3rd stage: data collection. At this stage, it was defined what would be extracted from the selected studies using a previously prepared instrument, with the purpose of organizing the key information in a concise manner for the construction of the study. ${ }^{9}$

4th stage: critical analysis of the included studies. In this phase, data analysis was carried out in detail to ensure the validity of the review. Always taking into account the guiding question as the basis for all analysis. ${ }^{10,11} 5$ th stage: discussion of the results. In this phase, the results obtained in the research were discussed and a critical analysis was carried out on what was evidenced. ${ }^{11}$ 6th stage: presentation of the integrative review. This is the stage where the study was properly prepared. Containing enough information for the reader to analyze the study. ${ }^{12}$

In order to guide this integrative review, the following question was elaborated: what scientific knowledge is available in the literature, about the use of a cardiological instrument in intensive care for medical and nursing care, with regard to the terminality of life and palliative care?

The articles were selected from the Virtual Health Library (VHL) database: LILACS (Latin American and Caribbean Literature in Health Sciences), BDENF - Nursing (Nursing Database); PubMed - MEDLINE (Medical Literature Analysis and Retrievel System Online) and Scopus. The descriptors used were:Elderly. Medicine. Nursing. Technology. Paliative Care. Cardiology, through the Boolean operators "AND" and "THE", with the objective of facilitating searches for materials indexed in the databases, in the databases that apply. $^{13}$

The research universe consisted of online articles in the health field, related to the use of cardiological instruments in intensive care for medical and nursing care in palliative care, through access to the

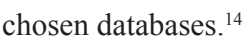

The sample was determined considering the following inclusion criteria: being available in the selected databases, contemplating the proposed theme, being available in full text, English or Portuguese, being article-type publications, in the period from 2010 to 2020. The criteria for exclusion were: dissertations and theses, be in Spanish, as well as complete texts not available and do not contemplate the proposed theme. ${ }^{15}$

Data collection was performed using an instrument (form) and occurred between August 2019. The information contained in that instrument aimed at characterizing and contributing to the selected publications, in order to meet the objectives proposed for the investigation. They are: identification of the article, professional training of the authors, database, year and origin of the publication, focus on the theme and contribution of the study. ${ }^{16-1899}$ articles were found, of which 50 did not answer the guiding question, 38 were repeated in the researched databases, which resulted in the selection of 11 articles to compose the sample of this integrative review. ${ }^{19-21}$

The information taken from the studies was collected in an instrument and graphics that gathered and summarized the key information. The data from the studies included in the research were categorized, analyzed and discussed, establishing relationships with the theoretical foundation in focus(Figure $1 \&$ Figure 2). ${ }^{22,23}$

\section{Results and discussion}

\section{Palliative care general context}

While the number of deaths from heart disease has not changed substantially since 1990 in developed countries, there has been a $66 \%$ increase in deaths in low- and middle-income countries. Due to disease characteristics, patients often need palliative care to relieve suffering and improve quality of life. ${ }^{23,24}$

Among chronic diseases, Congestive Heart Failure (CHF) has a higher rate of readmission and mortality, limiting life expectancy. Patients with advanced CHF often suffer from several physical and psychosocial symptoms. From a clinical point of view, CHF is 
more a gradual decline in cardiac function, with episodes of acute deterioration and slight recovery), - than an episode of sudden death. It affects $2 \%$ to $5 \%$ of adults between 65 and 75 years and more than $10 \%$ of those aged 80 and over, and it is not uncommon for the patient to receive aggressive treatment despite the poor prognosis. ${ }^{25}$
The Palliative Care (PC) model involves taking a series of measures well before the final stages of the disease, from the period close to death. Ideally, the PC should be juxtaposed to curative treatments in cases of poor prognosis, in a comprehensive patientcentered approach, taking into account their existential, psychosocial and clinical needs. ${ }^{26}$

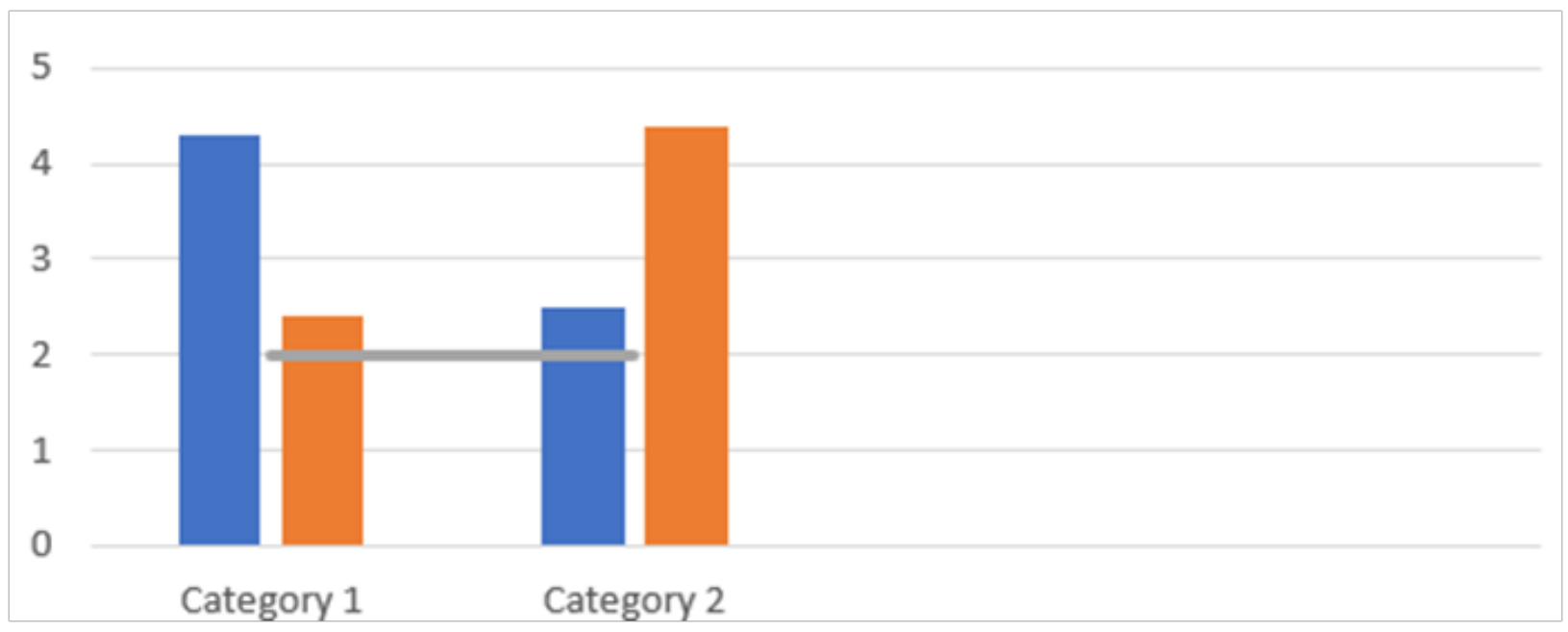

Figure I Suceessfull data collection statistical study satisfaction level.

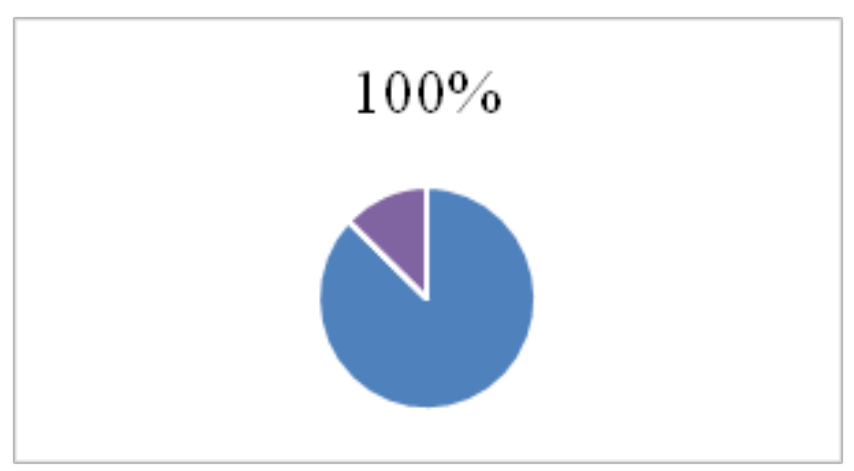

Figure 2 Statistical satisfaction of the method according to the quantity of articles.

The first step in offering CP to the population is to identify which individuals would need this type of care. Traditionally, PC needs were estimated from the causes of mortality, but, more recently, alternative methods of calculating prevalence or direct measures in the general population have been used), among them, tools that estimate the probability of death in a given period (usually 1 year). ${ }^{26} \mathrm{An}$ instrument capable of identifying patients who will need PC and predicting mortality would facilitate end-of-life planning, improve quality of life and assist managers in allocating resources efficiently. ${ }^{25,26,14}$

Palliative Needs (NECPAL) is a scale developed at the Collaborating Center of the World Health Organization of the Catalan Institute of Oncology to predict the mortality of chronic patients and thus allow the planning of care in the last year of life, having been applied in different clinical contexts. ${ }^{25}$ In a cohort designed to assess the mortality prediction of this scale at 12 months of follow-up,
NECPAL showed high sensitivity (91.3\% 95\% CI: 87.2-94.2\%) and high negative predictive value (91.0\% 95\% CI: 86.9-94.0). ${ }^{25}$

\section{Elaboration of a prototype (information and communication technology)}

The need to reduce deadlines and increase productivity, in addition to the competitiveness and demand for higher quality, has contributed to the greater complexity of the product and required a greater number of professionals involved in its entire development process. These aspects, allied to the peculiarities of the civil construction sector, have led to discussions for changes in the forms of management and in the tools used for the Product Development Process (PDP), especially with regard to the design stages. ${ }^{26}$ During the design process, the main guidelines of the projects are defined, which directly influence costs, deadlines and production methods. ${ }^{27}$ However, despite their evident importance, projects often have flaws, such as:

(a) incompatibilities between the different functional parts of the building;

(b) insufficient details of the information; and

(c) deficiencies in the communication of the designer's decisions, mainly due to the use of only two dimensions for representation.

These failures result in a significant portion of the problems faced during the construction and use of the building. ${ }^{27}$

In the design stage of detailing, there is an increase in complexity in the act of designing due to the wide variety of materials, the high degree of demand for architectural decisions related to aesthetics and the need to meet the constructibility. Thus, the elaboration of the projects must consider the interfaces with the production process and must occur through the use of tools that represent the 
different attributes of the product, in order to support decision making involving the level of detail appropriate to each stage of the project development.

In this sense, information technology has allowed designers to use software for three-dimensional representation, giving rise to virtual models of the product and enabling the representation of attributes not normally presented in a single two-dimensional design.

\section{Medical and nursing assistance in cardiac ICU: palliative care and the aid of prototype technology}

Discussing palliative care in the cardiac ICU can be paradoxical, in view of practices that seem to be incompatible, since elderly patients in terminal life may not benefit from the technologies available in this unit, in view of the irreversibility of the condition, which manifests itself in the multiple spheres of the patient. human being and announces death. But despite this, patients in end-of-life care in the ICU are frequent, receiving assistance that sometimes aims to revert the clinical condition, and now seeks to balance technological advances for the relief of suffering and the maintenance of comfort, which marks the (des) therapeutic proportionality. ${ }^{28}$

The process of caring for patients in the context of palliative care in the ICU is multifaceted, permeated by contradictions, negative feelings and unhumanized assistance. Coping with death is still a challenge, since it provides ethical and paradigmatic dilemmas, given that professionals are trained and trained based on the model that prioritizes disease and cure. ${ }^{29}$

In addition, death awakens professionals' awareness of their own finances, generating internal conflict, doubts about the effectiveness, objectives and relevance of the care provided. In particular, decisionmaking processes, especially if focused on a single person, generate questions about the ability to reverse the situation, resulting in therapeutic obstinacy. Medicine and nursing in this process generate different strands of care, as the use of a prototype created with the aim of helping differentiated assistance in the elderly in cardiac care, under palliative care is extremely innovative. ${ }^{29}$

This research portrayed the terminality of life in the cardiac ICU (elderly) from the perspective of the aforementioned specialty, but despite the evolutionary characteristics of the CI, for example, to facilitate the prognosis and prediction of survival when compared with other chronic diseases of evolution slow, the difficulties interpreted throughout the testimonies were similar to the context of a general ICU. ${ }^{30}$

It is necessary to think about different alternatives for assisting patients in end-of-life care in the context of the hospital. However, in the course of this process, the current situation does not exclude this client profile from the ICU, and the offer of palliative care is urgent whenever necessary. ${ }^{31}$

Among the contradictions and problems in the implementation of the integration model based on consultation with the specialist, it is noteworthy that many health professionals may not consider this type of activation necessary, as they consider comfort measures to be common in their practices., and for that reason, palliative care ends up not being recognized as a specialty. ${ }^{32}$

\section{Conclusion}

It is evident that the competences of the doctor and the nurse according to the use of the cardiological instrument in palliative care, in their perception, are related to the competences of applying the central constituents of the terminality of life in the proper and safer environment; To recognize and support the needs of family members; To promote continuous professional development and self-knowledge and provide physical comfort during the course of the disease.

It is observed that the core competences least mentioned by doctors and nurses are to meet psychological needs; Still to implement an interdisciplinary team work and develop interpersonal and communicational skills.

It is worth emphasizing the importance of developing this study, so that the academy has more access to research based on proven and lived evidence, since an instrument was elaborated and polished, justified and still statistically placed on the agenda for the appreciation of a newspaper valid scientific document for its dissemination.

It appears that a large part of the competencies recognized by doctors and nurses, during palliative care of the cardiac patient, is related to patient and family care, thus showing the valorization of bedside care by nurses, in providing care integral to the patient and his family, as well as the physical comfort of the patient during the end of life process.

Due to the main difficulties in applying skills during patient care, the need to strengthen the multiprofessional team and joint decisionmaking are reflected, in addition to the need for education of health professionals.

It is concluded, therefore, that there is a holistic care of the patient in palliative care, that it is necessary to delineate the skills of the professionals, as well as the joint performance of the multiprofessional team, with the sole objective of meeting the principles of care at the end of life, even with the creation of an instrument for this purpose.

\section{Acknowledgments}

None.

\section{Conflicts of interest}

The authors declare have no conflict of interest about the publication of this paper.

\section{References}

1. Souza MC, LinsDR, Saraiva CNR, et al. Risk factors related to falls in elderly: a reflective study. MOJ Gerontol Ger. 2018;93(4):131-132.

2. Godoi BB, Freitas LVB, Chaves AA, et al. Palliative care and public health an issue to be held. MOJ Gerontol Ger. 2020;5(1):23-25.

3. Concha-Cisternas Y, Guzmán-Muñoz E. Vestibular rehabilitation therapy in elderly with benign paroxysmal positional vertigo. MOJ Gerontol Ger. 2020;5(1):5-8.

4. Bando H. Adequate management for various problems of geriatric syndrome in elder diabetic patients. MOJ Gerontol Ger. 2019;4(6):265-267.

5. Rubio FM, sky MAT, Salcedo EEO. Labor reintegration: approach to the reality of the transplanted patient. MOJ Gerontol Ger. 2018;3(4):301-303.

6. Souza MC, Araújo HS, Silva, TTSM, et al. Treatment of venous ulcer in the elderly: implications for nursing. MOJ Gerontol Ger. 2018;3(4):287-291. 
7. Lima MCSC, Diniz MLSBERS, Valença CNGAV. Falls in the elderly: a reflective study. MOJ Gerontol Ger. 2018;3(5):366-368.

8. Viana, Yullia Abreu. Nursing professionals' conception on palliative care. International Archives of Medicine. 2016;1(9).

9. Caxias de Souza, Maurício. Contributions of nurses in health education of patients with heart failure. International Archives of Medicine. 2017; 1(9).

10. Souza, Maurício Caxias de. Male doula, why not?. International Archives of Medicine. 2017;1(9).

11. Azevedo da Silva, Thaís Dandara. Burnout syndrome in community health agents: an integrative review. International Archives of Medicine. 2016;1(9).

12. Bichara VM, Santillán J, Rosa R, et al. Depresión en insuficiencia cardíaca crónica: causa o consecuencia. Insuf Card. 2016;11(4):173200.

13. Luiz MM, Mourão Netto JJ, Vasconcelos AKB, et al. Palliative nursing care in the elderly in UCI: an integrative review. J Res Fundam Care Online. 2018;10(2):585-592

14. Gamondi C, Larkin P, Payne S. Competencias centrais em cuidados paliativos: um guia orientador da EAPC sobre educação em cuidados paliativos - parte 1. EJPC. 2013;20(2):86-91

15. Oliveira MC, Gelbcke FL, Rosa LM, et al. Palliative care: nurses vision of a teaching hospital. Enferm Foco. 2016;7(1):28-32.

16. Espinosa J, Martinez-Muñoz M, Lasmarias $\mathrm{C}$, et al. The WHO collaborating centre for public health palliative care programs. an innovative approach of palliative care development. $J$ Palliat Med. 2014;17(4):385-392.

17. Batiste XG, Martínez-Muñoz M, Blay C, et al. Utility of the NECPAL tool and the surprise question for early palliative care to predict mortality with chronic conditions: a cohort study. Palliat Med. 2017;31(8):754-763

18. Martín-Lesende I, Recalde E, Viviane-Wunderling P, et al. Mortality in a cohort of complex patients with chronic illnesses and multimorbidity: a descriptive longitudinal study. BMC Palliat Care. 2016;15:42.

19. Bocchi EA, Marcondes-Braga FG, Bacal F, et al. Sociedade brasileira de cardiologia. Atualização da diretriz brasileira de insuficiência cardíaca crônica - 2012. Arq Bras Cardiol. 2012;98(1 Supl.1):1-33.
20. Klindworth K, Oster P, Hager K, et al. Living with and dying from advanced heart failure: understanding the needs of older patients at the end of life. BMC Geriatr. 2015;15:125.

21. McClung JA. End-of-life care in the treatment of heart failure in older adults. Heart Fail Clin. 2017;13(3):633-644.

22. Burlá C, Goreti M. Prognóstico: doença cardíaca. In: Carvalho R, Parsons H, organizadores. Manual de cuidados paliativos. $2^{\mathrm{a}}$ ed. Rio de Janeiro: Diagraphic; 2012:58-62.

23. Gómez-Batiste X, Martínez-Muñoz M, Blay C, et al. Utility of the NECPAL CCOMS-ICO (c) tool and the surprise question as screening tools for early palliative care and to predict mortality in patients with advanced chronic conditions: a cohort study. Palliat Med. 2017;31(8):754-763

24. Dang S, Karanam C, Gómez-Marín O. Outcomes of a mobile phone intervention for heart failure in a minority county hospital population. Telemed J Health. 2017;23(6):473-784.

25. Santos CE, Caldas JMP, Serafim JA, et al. Palliative care in Brazil: with a view to future needs?. Int Arch Med. 2017;10:1-9.

26. Ziehm J, Farin E, Schafer J, et al. Palliative care for pactients with heart failure: facilitators and barriers - a cross sectional survey of German health care professionals. BMC Health Serv Res. 2016:16(a):361.

27. Ziehm J, Farin E, Seibel K, et al. Health care professionals' attitudes regarding palliative care for patients with chronic heart failure: an interview study. BMC Palliat Care. 2016.

28. Worldwide palliative care alliance, world health organization. Global atlas of palliative care at the end of life. Geneva: WHO; 2014.

29. World health organization. Palliative care. Geneva: WHO; 2018.

30. Rafkin HS, Hoyt JN. Objective data and quality assurance programs: current status and future trends. In: Sichuster DP, Kollef MH. Editors. Intensive care clinics: prognosis in the ICU. Rio de Janeiro: Interlivros; $2017 ; 161-82$.

31. Terzi R, Guelli E, Abreu HJ, et al. Prognostic indices in intensive care II: methods. Rev Bras Terap Intens. 2018;9(1):40-49.

32. Terzi R, Guelli E, Abreu HJ, et al. Prognostic indices in intensive care I: concepts. Rev Bras Terap Intens. 2019;5(4):101-106. 